\title{
少数民族地区高中英语课堂学生自主提问的调查与思考
}

\author{
陈雁翔
}

广西师范大学外国语学院

DOI:10.32629/er.v2i12.2219

[摘 要] 本文通过问卷调查和访谈,对贵州省黔西南民族自治州一所示范性高中的英语课堂自主提问总体情况、性别差异及年级差异进行个案 调查研究。结果表明: 学生有较高的自主提问意识但与实际提问行动不符; 学生在自主提问上存在性别差异和年级差异,基于该现状,教师可通 过转变课堂提问模式、训练学生自主提问技巧、培养学生自主提问的积极态度和提高学生英语口语水平的方法, 改善课堂中学生自主提问能力 欠缺的问题。

[关键词] 少数民族地区; 高中英语课堂; 学生自主提问; 现状; 差异

培养具有创新思维能力、自主学习能力和合作学习能力的人才是高中 英语教学的主要目标之一, 要培养出有创新思维的人才, 首先要培养起学 生的提问意识和提问能力。然而, 少数民族地区与发达地区相比, 还存在一 定差距。目前少数民族地区的高中英语教学现状显示, 课堂上教师提问占 主导, 汉语为常规英语课的主要课堂用语, 能运用三语优势激发学生提问 兴趣的少数民族英语教师资源短缺, 少数民族地区学生因此处在较被动的 学习氛围中, 不愿意提问、害怕提问和不知道如何提问, 一定程度影响了学 生核心素养的形成。

近年来, 大批学者在学生自主提问的领域进行了多种研究, 研究结 果证明学生在课堂中的自主提问不仅对学生的学习和教师的教学发挥 着诸多积极作用, 而且益于课堂积极学习氛围的营造。因此, 研究少数民 族地区高中英语课堂学生自主提问的现状, 探讨适合当地教师教学的改 进方法, 以期促进少数民族地区学生英语学习能力和思维能力发展, 很 有必要。

\section{1 高中英语课堂学生自主提问现状}

1. 1 研究对象和方法

本文选取贵州省黔西南民族自治州兴义中学高一和高二年级学生为 调查对象, 发放问卷350份, 回收问卷339份, 有效问卷336份, 有效率为 $96 \%$ 。 问卷维度包括提问意识、提问频率、提问类型、提问障碍、提问的准备时 间和提问方式六项, 通过SPSS分析数据后, 本文结合学生访谈进行深层次

\section{互换岗位。}

3. 4.3 对口支援: 大学高年级学生到农村顶岗实习或者实习等。这样 可以逐步缩小城乡教师队伍之间的差距。

3. 5 加强家长教育, 更新教育观念

3. 5.1 设置家长教育栏。要加大宣传力度, 让幼儿家长充分认识到幼儿 教育的重要性, 转变家长的教育观念, 在社会上形成一种关心幼儿、支持幼 儿教育事业的新风尚。幼儿班可以为家长设置宣传栏、黑板报、给父母推 荐一些儿童读物; 对于家长提出的热点问题应尽可能的解答; 让有先进经 验的家庭教育者做专题讲座。

3. 5. 2开设公开课。幼儿班应定期邀请幼儿家长到园观察幼儿的一日生 活、参加比赛、竞赛活动等。以增加家长对幼儿教育科学性, 趣味性的认识。

3. 6 鼓励男性从事幼儿教育工作

据我本人调查, 目前农村幼儿教师中男性的比例为零, 面对这一状况, 国 家应制定合理的激励政策, 鼓励优秀的男性加入到中小学教育以及幼儿教育 队伍中来。如, 从教师来源说, 出台相关的激励制度, 扩大师范类院校男生的招 收比例, 或是对家庭贫困的男性师范学生设额外的助学金, 对学习成绩优秀的
原因的进一步探究。

\section{2 研究结果与分析}

1.2.1学生提问意识高但行动力较差

根据问卷结果, 在提问意识方面, $85.2 \%$ 认为发现问题很有必要, $73.6 \%$ 认为应该在课堂上提出问题。然而, 在提问频率方面, 仅 $34.3 \%$ 的学生表示 自己经常提问。在提问类型方面, $41.7 \%$ 的学生提问长难句的意义和结构分 析, 33. 1\%提问与课文理解相关的问题, 27. 4\%提问生词的发音和含义, 只有 23. 5 \% 会提问课文的背景知识, 深层次提问较少, 较高层次问题类型单一, 然而不确定自己提问问题类型的学生仍占 $35 \%$ 。在提问障碍方面, 英语口语 水平和性格原因是大部分学生课堂提问少的主要内因。在提问方式 上, 66. 1\%的学生表示更青睐于通过小组合作的方式进行提问。

\subsection{2男女学生在提问类型和提问障碍上存在差异}

问卷结果显示, 对于细节分析问题的偏好, 女学生占 $43.3 \%$, 对于课文 内容理解问题的偏好, 男学生占 $47 \%$ 。就内部障碍而言, 男学生更易将课堂 不提问归因于性格因素和英语口语水平, 就外部障碍而言, 男学生更易归 因于课文难度过大和提问训练的缺乏。因此, 男女学生在提问问题的类型 上有各自较明显的倾向, 男学生在提问上面临的障碍比女学生更多。

1.2. 3 高一年级学生和高二年级学生在提问的外部障碍上存在差异

问卷结果表明, $45.4 \%$ 的高一学生会因为教师消极态度而不愿意在课 堂上提出问题, 反之, $44.5 \%$ 的高二学生则不会因为教师态度而影响课堂提

男性师范生特设奖学金, 进一步提高教师的待遇。除此之外, 还要注意提高他 们的社会责任感、使命感、荣誉感, 发挥他们的个性特长, 使之有更加广泛的 用武之地, 矢志不渝地投身幼教事业, 为幼儿的健康成长发挥更大的作用。

\section{4 结束语}

综上所述, 西北农村幼儿教育现状主要表现为办学条件简陃; 农村幼 儿教育师资力量薄弱, 教师男女比例严重失调; 家庭学校教育脱节, 教育观 念陈旧落后; 教学内容小学化, 娱乐活动城市化; 外出民工子女幼儿教育 得不到保障等。因此针对现状需要采取相应的措施, 从而有效提升西北农 村幼儿教育水平。

\section{[参考文献]}

[1]刘绪, 周仁会. 农村幼儿教育现状分析及对策 [J].四川职业技术学 院学报,2008,(01):70-72.

[2]张家智.全民教育视野中农村幼儿教育存在的问题及对策——以 安徽省金寨县南溪镇为例 [J]. 大庆师范学院学报,2010,30(04):138-140.

[3]王晓青. 农村幼儿教育存在的问题与对策[J]. 重庆电子工程职业学 院学报,2009,18(03):129-130. 
问的意愿。另外, $52.6 \%$ 的高二学生还表示自己未缺乏一定的提问技巧训练, 高一学生认为缺乏提问训练的占 $60.8 \%$ 。由此可见, 大部分高二学生在应对 课堂提问时比高一学生表现得更适应。

\section{2 高中英语课堂学生自主提问现状原因分析}

2. 1教师和学生有心理负担

传统教学下教师向学生强调提问意义和必要性的侧重点更多放在让 学生及时解决课后练习和试卷上的错题, 处在分数竞争压力下的学生, 提 问意识自然较高。而提问意识与提问实际行动不相符的原因可能在于, 学 生往往更多被鼓励在课下提问, 或被建议经过三思后再进行提问, 一定程 度上学生被隐性传递了 “课上提问问题较花费时间和不要问蚟问题” 的观 念。要求学生课下提问问题, 往往由于教师害怕承担过多的心理负担, 例如 对课堂提问活动设计的考虑和应对学生出其不意问题的准备 (王 坤, 1998)。

在学生方面, 内向性格也会成为提问频率低的原因, 不同的性格特质 会为是否将提问意识转化成实际创造能力而提供不同的条件 (俞国良, 侯 瑞鹤, 2003), 但从学生的访谈结果看, 学生往往不喜欢承认是自己的内向 导致提问频率低, 学生担心内向是怯懦的代名词, 而更倾向表示自己是因 为喜欢聆听多于表达。另外, 采访学生也表示, 对影响教师上课节奏的顾 虑、对浪费同学们听课时间的担忧以及自身缺乏较扎实的英语语言组织和 表达能力同样导致他们较低频率的课堂提问。

\section{2 课堂缺乏动态学习}

英语考试阅读注重学生分析长难句获取有效信息的能力, 英语教师往 往在课堂上着重讲解该类型问题, 学生会因此认为该类问题最值得提问, 学生面临如此紧张的学习压力和处在快节奏的提问氛围之中, 也解释了高 二学生比高一学生更适应课堂提问的原因。Huang et al (2017) 的研究也 表示, 教师对学生将来高考的担忧和对不属于教学目标范围的问题的忽视, 会打击学生提问高认知能力问题的积极性, 因此学生普遍深层次提问较 少、较高层次问题类型单一。在学生访谈中, 学生表示被动的课堂学习气 氛、缺乏足够活跃度的小组学习以及思维惰性造成的对知识的片面满足也 是他们课堂提问动力缺乏的原因。

\section{3 民族心理和性别心理的双重影响}

高自尊学生可能更害怕在公众提出问题而暴露无知 (Graesser, 1993), 而有着社会修正障碍的学生更易于在课堂中保持拘谨和保守态度, 以便树 立起纪律良好的形象而获得长辈的表扬 (Berk, 2001)。这样的民族心理在 中国课堂上有迹可循, 学生往往善于沉默, 不愿冒进, 尝试去表达可能与他 人不同的疑问和见解。黔西南地区民族多为布依族、苗族、彝族, 过去稳 定的生活方式让黔西南地区的民族有别于游牧生活的激烈、开放和活泼, 因此更倾向于中和、宁静和保守 (黄守斌, 韦磐石等, 2009), 少数地区学生 的成长自然脱离不开民族心理的影响。此外, 男学生更在乎公众面前的语 言运用能力, 男学生往往对运用语言优势抓住中心地位拥有高的期待 (Tannen, 1991), 而通过访谈发现, 女学生在英语基础方面比男学生更为扎 实, 男学生心理上的高期望和现实水平形成过大差距, 因此更挫伤课堂提 问的动力。

\section{3 改善少数民族地区高中英语课堂学生自主提问的教学对策}

3. 1转变教学模式

教师应善于运用学生较高的自主提问意识, 将教师主导提问模式转换 为教师提问与学生提问相结合的模式, 为消除部分学生对影响教师上课节
奏的顾虑和对浪费同学们听课时间的担忧, 教师应在活动设计上掌握主动 权, 在不偏离教学大纲和教学目标的前提下, 明确学生在英语课堂上自主 提问的一定时间量。

3. 2 训练学生的提问技巧

教师可向学生系统传授提问的不同类型。其次, 教师应使学生掌握有 效的提问技巧, 引导学生进行从易到难的渐进式练习, 开始阶段以 “ $5 \mathrm{~W} 1 \mathrm{H}$ ” 模型训练问题生成, 如 “What if...”, “Why does...”, “Why are...”, “ How would...” , 再提升到深层次思考的问题, 如 “What is the difference between. . . and. . ?? , “How does... affect. . ?? and "What are the strengths and weaknesses of...”等。同时, 教师也需特别注 意给予学生问题生成的平等机会和时间, 注意男女学生提问类型倾向性的 差异, 多引导和鼓励男女学生思考其他类型的问题。

3. 3培养学生对自主提问的积极态度

为减轻学生课堂提问的心理负担, 初期可先引导学生笔头书写问题, 再逐步过渡到口语表达提出问题。教师可利用群体动力学组建个体差异和 性格因素能得到尊重的英语学习小组, 让学生产生共享的学习责任感。多 鼓励男学生进行课堂英语提问, 让学生感受到一定的学习成就感, 树立起 提问的信心, 也坚定今后学习的毅力。通过设立评价或奖励机制的方法, 培养高一学生在自主提问上积极态度。

3. 4 提高学生的英语口语水平

由于学生的英语表达受到自己本民族语言和汉语的影响, 学生的口语 水平普遍较薄弱, 教师可确立英语为主要课堂语言的方式, 对学生给予足 够量的英语语言输入。另外, 教师还可运用三语优势缓解少数民族学生对 英语表达的畏难情绪, 运用与学生民族文化息息相关的例子, 展开不同民 族间语言表达的对比。

\section{[参考文献]}

[1]Berk,L.E.Awakening Children’ s Mind[M]. London:0xford University Press,2001:27.

[2]Graesser,A.C.,Person,N.Question Asking During Tutoring[J].American Educational Research Journa1,1994,31(1):104-137.

[3]Huang,X.,Lederman,N.G.\& Cai,C.Improving Chinese Junior High School Students' Ability to Ask Critical Questions[J].Journal of Research in Science Teaching,2017,54(8):963-987.

[4]Tannen,D.Teachers' Classroom Strategies Should Recognize that Men and Use Language Different7y[N].The Chronicle of Higher Education, 1991,(40):B3.

[5]黄守斌,韦磐石,张军,等.黔西南布依族文化审美心理现象探析一 黔西南布依族文化心理的发展与变迁[J].黔西南民族师范高等专科学校 学报,2009,(04):38-41.

[6]王坤.鼓励学生自己提问题[J].学科教育,1998,(07):14-16.

[7]俞国良,侯瑞鹤.问题意识、人格特征与教育创新中的创造力培养 [J].复旦教育论坛,2003,(04): 11-15.

\section{作者简介：}

陈雁翔(1993--), 女, 汉族, 广西玉林人,广西师范大学外国语学院, 教育硕士,研究方向：英语教学。

\section{基金项目:}

“广西研究生教育创新计划项目”,课题编号“XYCSW2019039”。 